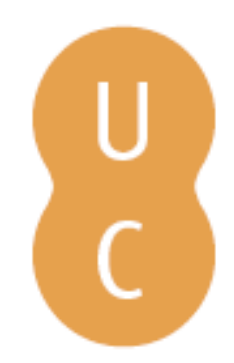

\title{
pommalina
}

\section{O Observatório astronómico (1772-1837)}

\author{
Autor(es): $\quad$ Figueiredo, Fernando B.
}

Publicado por: Imprensa da Universidade de Coimbra

URL

persistente: URI:http://hdl.handle.net/10316.2/38513

DOI: $\quad$ DOI:http://dx.doi.org/10.14195/978-989-26-0610-1_2

Accessed : $\quad$ 26-Apr-2023 14:11:17

A navegação consulta e descarregamento dos títulos inseridos nas Bibliotecas Digitais UC Digitalis, UC Pombalina e UC Impactum, pressupõem a aceitação plena e sem reservas dos Termos e Condições de Uso destas Bibliotecas Digitais, disponíveis em https://digitalis.uc.pt/pt-pt/termos.

Conforme exposto nos referidos Termos e Condições de Uso, o descarregamento de títulos de acesso restrito requer uma licença válida de autorização devendo o utilizador aceder ao(s) documento(s) a partir de um endereço de IP da instituição detentora da supramencionada licença.

Ao utilizador é apenas permitido o descarregamento para uso pessoal, pelo que o emprego do(s) título(s) descarregado(s) para outro fim, designadamente comercial, carece de autorização do respetivo autor ou editor da obra.

Na medida em que todas as obras da UC Digitalis se encontram protegidas pelo Código do Direito de Autor e Direitos Conexos e demais legislação aplicável, toda a cópia, parcial ou total, deste documento, nos casos em que é legalmente admitida, deverá conter ou fazer-se acompanhar por este aviso.

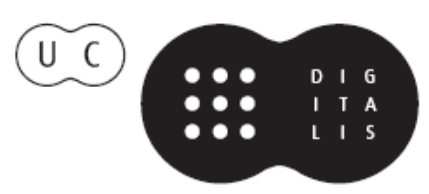



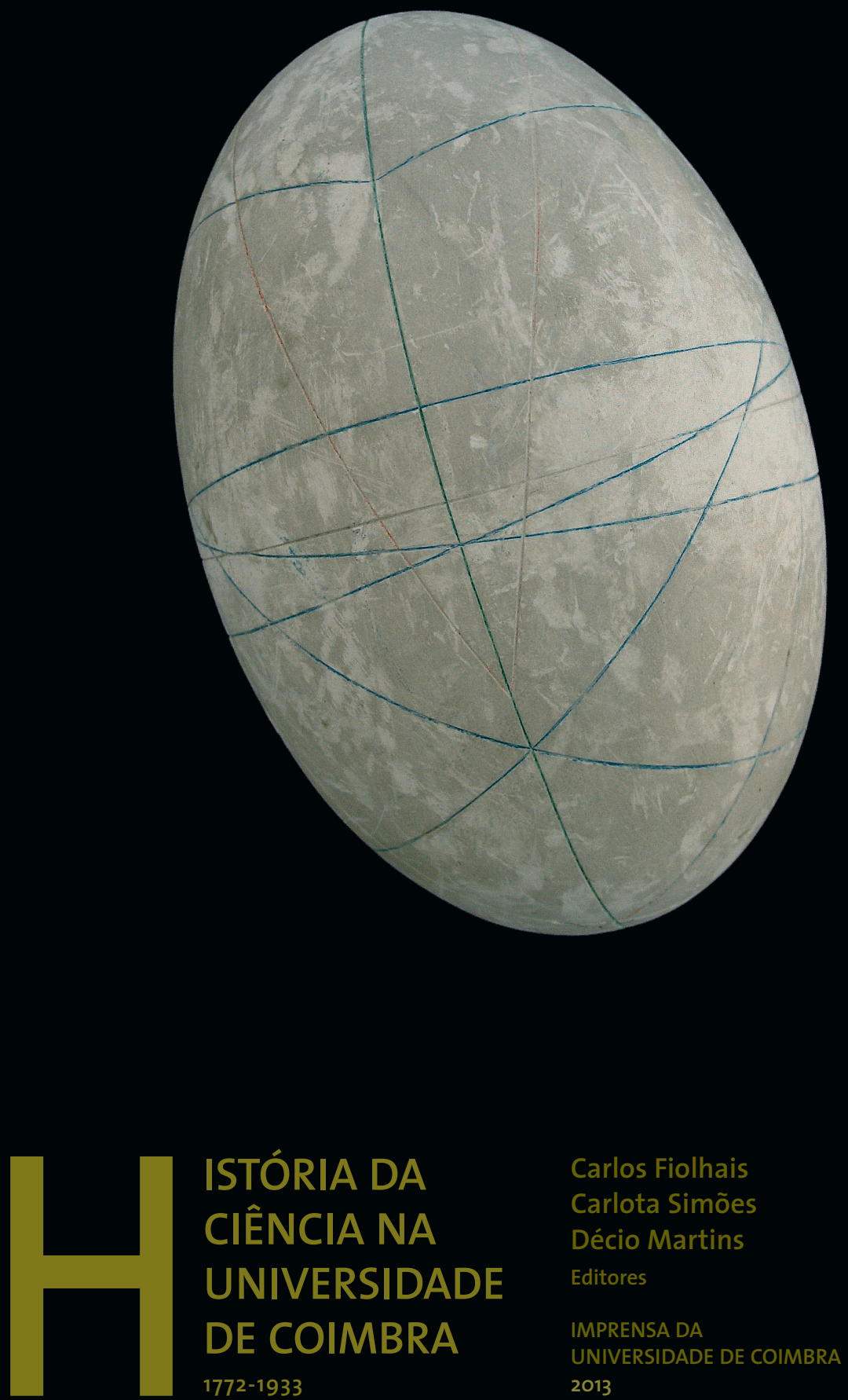

ISTÓRIA DA

CIÊNCIA NA

UNIVERSIDADE

DE COIMBRA

1772-1933
Carlos Fiolhais

Carlota Simões

Décio Martins

Editores

IMPRENSA DA

UNIVERSIDADE DE COIMBRA

2013 
Centro de Geofísica da Universidade de Coimbra - Centre François Viète.

Université des Nantes.

O ObSERVATÓRIo Astronómico (1772-1837) ${ }^{1}$

Fernando B. Figueiredo

A ideia de criar um Observatório Astronómico surge desde logo nos Estatutos Pombalinos (1772) a propósito da Faculdade de Mathematica e da respectiva cadeira de Astronomia (.$^{\circ}$ ano). A sua criação tinha dois objectivos distintos, a leccionação e o desenvolvimento da ciência astronómica. Os Estatutos Pombalinos encaravam a ciência como a força motriz para uma mudança de mentalidades essencial à modernização do país e a astronomia desempenhava um papel fundamental pelas "consequências tão importantes ao adiantamento geral dos conhecimentos humanos, e à perfeição particular da Geografia, e da Navegação". Por isso o Observatório Astronómico era representativo desse modo de ver a ciência, constituindo simultaneamente um meio para o seu desenvolvimento. Através dele Portugal sintonizar-se-ia com a Europa científica do seu tempo - "Tem merecido em toda a parte a atenção dos Soberanos, fazendo edificar Observatórios magníficos, destinados ao progresso da Astronomia." Contudo, apesar dos Estatutos estipularem desde logo a edificação do Observatório a verdade é que só em 1799 a Universidade se vê dotada com este estabelecimento científico.

O papel e a prática astronómica que se requeriam para o Observatório (traçados logo nos Estatutos e depois reforçados no seu regulamento, C.R. de 4-12-1799) prendem-no a uma dicotomia muito própria: por um lado como observatório universitário e por outro como observatório nacional. Um programa astronómico que lhe confere a característica de observatório nacional, envolvendo-o na elaboração e publicação das Efemérides Astronómicas - "Para o Meridiano do Observatório, e para uso dele (assim como se pratica nos mais célebres da Europa) se calculará a Efeméride Astronómica, a qual igualmente possa servir para uso da Navegação Portuguesa” -, e alguns aspectos que, também, o caracterizam como observatório universitário: a leccionação, onde os alunos deveriam ter aulas práticas - "fazendo-se adquirir aos Ouvintes o hábito, e prontidão necessária nos Cálculos Astronómicos, e na prática das observações [...]"2; e a investigação científica dos professores, para que "trabalhem

${ }^{1}$ Adaptado de Fernando B. Figueiredo [2012, no prelo]. A criação do Observatório Astronómico da Universidade de Coimbra (1799) e o estabelecimento do seu programa científico, Actas do Colóquio 'Espaços e Actores da Ciência em Portugal (XVIII-XX)', FCSH-UNL

2 “[...] Para isso distribuirá os discípulos em turmas, que lhe assistirão no Observatório pelos seus turnos [...] e lhes ensinará o uso dos Instrumentos, fazendo muito por formá-los na precisão, e delicadeza escrupulosa, que distingue os Grandes Observadores, úteis ao progresso da Astronomia" [Estatutos 1772, v.3 p.195, 203]; "com 
com assiduidade em fazer todas as Observaçôes [...], para se fixarem as Longitudes Geográficas; e rectificarem os Elementos fundamentais da mesma Astronomia” [Estatutos 1772 , v.3 p.213].

No que diz respeito à actividade do Observatório Astronómico, só a partir de 1799 este passa a ser um verdadeiro estabelecimento científico. Até meados da década de 1780 o observatório interino, que havia sido construído por volta de 1775-77, desempenhara quase em exclusivo uma função pedagógica, servindo principalmente como estabelecimento de ensino prático. A partir de meados/finais dessa década o observatório vê-se dotado do acervo instrumental que lhe permite passar a outro patamar: o de estabelecimento científico. Porém enfrentava um grave problema, a falta instalaçôes para as necessárias e diversas valências ao seu pleno funcionamento.

\section{Observatório Astronómico: Vicissitudes da sua Construção}

Hoje, a maior parte dos muitos visitantes que franqueiam a Porta Férrea da Universidade e olham, ao entrar no Pátio das Escolas, à sua esquerda e se aproximam do varandim para desfrutar a imensa vista sobre a baixa da cidade e do rio Mondego, não faz ideia que aí era durante muitos anos (quase 150) o Observatório Astronómico da Universidade de Coimbra (OAUC) - um edifício de configuração rectangular, "constituído por três corpos contíguos em que o central é três vezes mais alto do que os laterais." [Bandeira 1943-1947, p.129] -, e que foi demolido aquando das obras de requalificação da Universidade de Coimbra nos anos 50 do século XX (fig.1). Porém, este edifício não foi aquele que a Reforma Pombalina previu edificar. O sítio que se determinou primeiramente para a construção do Observatório foi o Castelo da cidade [Lemos 1777, p.260], que se situava na vertente da Alta de Coimbra oposta ao Paço das Escolas, onde hoje é o Largo D. Dinis (no cimo das Escadas Monumentais).

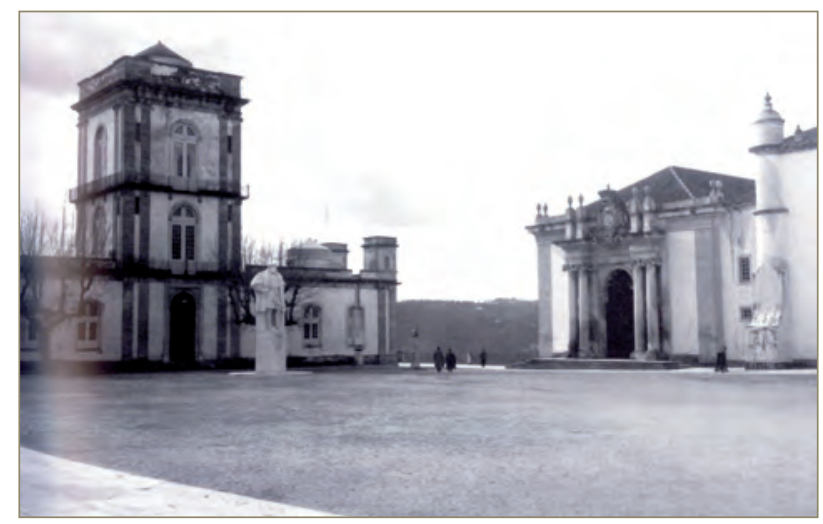

Figura 1 - Observatório Astronómico da Universidade de Coimbra (OAUC) - um edifício de configuração rectangular, constituído por três corpos contíguos em que o central era três vezes mais alto do que os laterais.

o cuidado expresso de distinguir e não deixar interferir as aulas e a prática lectiva com as observações e práticas astronómicas quotidianas do Observatório" [C.R 4-12-1799, \$.9]. 
O sítio do Castelo da cidade para além de corresponder a um dos principais requisitos que um edifício desta natureza exigia, o ser edificado num lugar alto e "desassombrado por todas as partes" [Estatutos 1772, v.3 p.214] ${ }^{3}$, desempenharia também um papel simbólico na própria Reforma Pombalina. A monumentalidade da Reforma espelhava-se na obra arquitectónica dos vários estabelecimentos científicos, dos quais sobressairia pela monumentalidade e localização o Observatório Astronómico. É com base neste programa que o arquitecto e engenheiro Guilherme Elsden (?-1779) irá desenvolver as duas versões conhecidas do projecto para o edifíción.

O Castelo era constituído por duas torres: a de menagem quadrada, de construção afonsina, a que se chamava Torre Nova; e uma segunda, de configuração pentagonal que embora fosse de construção mais recente, pois havia sido erguida nos tempos de D. Sancho I, era designada por Torre Velha [Lobo 1999, p.4].

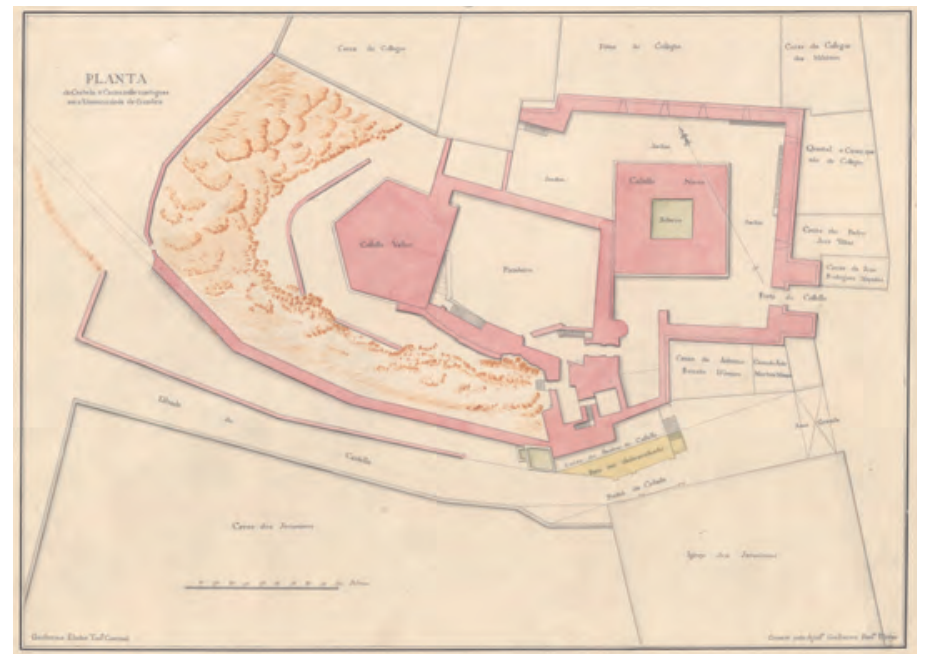

Figura 2 - Planta do Castelo e Casas a ele contíguas em a Universidade de Coimbra (Elsden, 1773).

[BGUC, Ms.3377/41]

$\mathrm{Na}$ tentativa de aproveitar as duas torres é delineada uma primeira versão para o projecto do observatório constituído por um volume com três pisos organizado a partir do aproveitamento das duas torres, enquadrando-as nos topos laterais do edifício a construir.

3 "O dito Observatório deverá ser desassombrado por todos as partes; de sorte, que dele se domine livremente o Horizonte; e se possam observar todos os Fenómenos, que sucederem no Hemisfério superior. Além disso deverá ser amplo, e cómodo; para nele poderem diversos Astrónomos observar ao mesmo tempo o mesmo Fenómeno: Tendo-se grande atenção em dispor as janelas com tal artifício, que se possam fazer as Observações nocturnas em quaisquer distâncias do Zénite, sem os Observadores serem incomodados pelo sereno." [Estatutos 1772, v.3 p.214].

${ }^{4}$ Guilherme Elsden chega a Coimbra em inícios de Março de 1773 [DRP 1937-1979, v.1 p.80] e no final do mês começam os preparativos da obra com a demolição do Castelo medieval e a regularização do terreno. Os trabalhos começaram em 29 de Março de 1773 com 64 trabalhadores desmanchando as paredes velhas do Castelo [ANTT Mç.513 Ministério do Reino]. Na semana que finda em 3 de Abril de 1773 são pagos os primeiros ordenados e despesas referentes à obra [AUC Liv.1 Est.10 Tab.2 n.15]. 


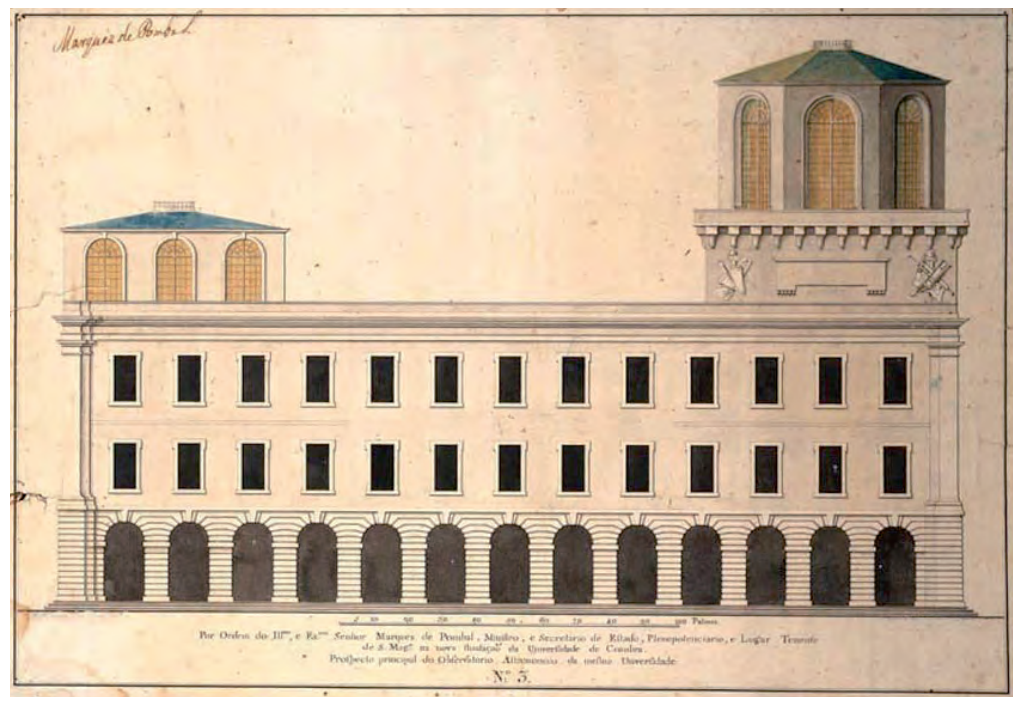

Figura 3 - Alçado do Observatório do Castelo (Elsden, c.1773). [MNMC, Inv. 2945/DA 23]

Assim temos um piso térreo porticado em silharia de junta fendida, com treze vãos formados por arcos de volta perfeita em correspondência aos treze vãos em cada um dos dois pisos superiores, definindo um bloco maciço enquadrado pelas pilastras laterais e entablamento superior de grande contenção e sobriedade, com as duas torres a projectarem-se nas extremidades. À esquerda uma formação aparentemente quadrangular com três vãos por lado, à direita, e assente em estrutura quadrangular rematada por mísulas (com assentamento para uma inscrição ausente e ladeada pela iconografia relativa ao observatório), a outra torre de definição octogonal com um vão em cada um dos lados do octógono. A cobertura apresenta o remate coroado por pequenos balaústres [Martins \& Figueiredo 2008]. Esta proposta foi discutida e trabalhada com os vários professores da Faculdade de Matemática, principalmente com Miguel Ciera (1725?-1782), à data o professor da cadeira de Astronomia [Lemos 1777, p.126] e [ANTT MNR Ms.513].

Ao que parece que a torre pentagonal não estava em bom estado de conservação e é demolida, avançando-se assim para outra versão onde a Torre Nova de forma quadrada vai constituir o elemento fundamental, situando-se no centro da composição e não de um dos lados. Com esta segunda versão, ao deslocar-se a implantação do edifício para mais próximo do Colégio de São Jerónimo, ou seja, ao ficar centrado na torre quadrada, evitava-se um embasamento muito maior, podendo-se assim endireitar o terreno e "formar-se uma planta regular", como o reitor Francisco de Lemos (1735-1822) afirma. Esta segunda versão, a mais monumental das propostas para o Observatório do Castelo, será aprovada no último trimestre de $1773^{5}$.

\footnotetext{
${ }^{5}$ Esta é a versão final do observatório astronómico do Castelo, aquela que é apresentada por Francisco de Lemos à Rainha ([Lemos 1777], [Franco 1983]). Na verdade ao longo de todo o ano de 1773 houve imensas indefiniçôes relativas ao projecto definitivo, com várias e sucessivas plantas a serem desenhadas e discutidas (de que hoje se desconhece o paradeiro e que creio mesmo que não será fácil encontrá-los!). No Ofício de 15-4-1773
} 




Figura 4 - Elevação Geométrica da frente principal do Observatório Astronómico da Universidade de Coimbra. [Franco 1983]

Estamos perante o projecto de um edifício de dois pisos, porticado no piso térreo, e encimado por um corpo recuado onde se eleva, ao centro da composição, a torre do observatório faz o aproveitamento da torre de menagem afonsina de planta quadrada. Neste projecto, um dos mais belos projectos de Elsden para a Universidade, a galeria porticada do piso térreo, em cantaria de junta fendida, clarificava a função urbana de porta: iniciar o acesso à Rua Larga e prolongar o Passeio Público que vinha desde o já idealizado Jardim Botânico, em confronto com o Colégio de S. Jerónimo; implantava-se no local onde desembocava uma das mais importantes vias de acesso à Alta. O Observatório Astronómico tem assim um forte poder simbólico, pois representa ele próprio o paradigma de uma monumental Reforma: a Reforma dos estudos universitários como um todo e a reforma dos estudos das "Sciencias Naturaes" em particular'.

Em 1775 (a partir do mês de Setembro) quando estava realizado o essencial do piso térreo, com o edifício erguido até ao $1 .^{\circ}$ piso, "a uma altura não inferior a 8 metros", as obras param. O elevado custo dos trabalhos atingido em cerca de dois anos e meio, e quando estava ainda por realizar parte significativa da obra, é a prin-

começam a ser discutidas e aprovadas as plantas das obras [DRP 1937-79, v.1 p.69]. Três meses depois (24-6-1773) o Reitor informa que as obras preparativas para a construção do edifício haviam entretanto começado, estando o Castelo já desembaraçado das muitas paredes velhas que eram necessárias demolir para fundar o edifício [Braga 1898-1902, v.3 p.470]. Em 3-9-1773, ao que parece, as plantas estavam quase prontas com as obras de preparação ainda a decorrer [Braga 1898-1902, v.3 p.504].

${ }^{6} \mathrm{Na}$ Provisão de 16-10-1772 o próprio Marquês faz questão de referir essa função simbólica do edifício: "para que a entrada para o mesmo Observatório e para a Rua Larga dos Colégios, sendo uma das principais e mais úteis, e necessárias fique em benefício público dos Académicos, e dos habitantes de Coimbra livre e desembaraçada dos impedimentos, e perigos que nela se acham; e constituindo uma das porções mais formosas da mesma Cidade naquela parte destinada aos passeios públicos". A respeito do discurso arquitectónico da própria Reforma Pombalina vejam-se [Pimentel 2000] e [Craveiro 2004]. 
cipal causa para a interrupção de tão ambicioso projecto ${ }^{7}$. Entretanto, o Reitor, D. Francisco de Lemos (1735-1822), consciente do tempo que levaria a pôr de pé tal equipamento mandou construir para uso das aulas um pequeno observatório interino (de caracter provisório) no terreiro do Paço das Escolas ${ }^{8}$. A escolha deste local para a construção deste pequeno edifício provisório, que foi realizado de imediato, representa uma opção que era admitida pelos próprios Estatutos, a da comodidade: "procure escolher o lugar, que para o sobredito Observatório for mais próprio; na maior vizinhança da Universidade, que couber no possível; quando não haja a comodidade para o estabelecer dentro nos Paços dela”. Distante dos acessos à Alta, e por isso mais recatado, o local dispunha de um amplo espaço aberto sobre o vale do Mondego. Esta condição talvez explique a posterior escolha deste local, nos finais da década de 1780, para a edificação do definitivo Observatório Astronómico da Universidade (OAUC). O observatório interino terá sido então construído entre 1775 e $1777^{9} \mathrm{e}$ com o passar dos anos vai sendo alvo de algumas obras e pequenas requalificações. Deverá ter inclusive sofrido uma ampliação, pois são feitos pagamentos em 1784 ao que se chama "novo acrescento do Observatório dentro da Universidade" (explicando-se assim as despesas que para ele se encontram nos arquivos). Em 1787 é alvo de mais intervenções [ANTT Mç.517 Ministério do Reino]. Este pequeno edifício provisório, construído na década de 1770 , e que será alvo de contínuos melhoramentos até c. 1787 , terá servido até cerca de 1790 , data em que se começa a construção do definitivo OAUC, quase em exclusivo para o uso das aulas. (Terá sido demolido aquando da construção do definitivo OAUC, que irá aproveitar parte do espaço que o observatório interino ocupava [Figueiredo 2011, pp.283-305]).

O problema da efectiva falta de um verdadeiro Observatório Astronómico na Universidade exigia uma solução. Será por volta por volta de 1785-87 que tal se começa a desenhar. Terão sido várias as razões para que só por volta desta altura a questão da falta de um verdadeiro Observatório Astronómico volte a estar em cima da mesa. Uma deve-se a questôes internas à própria astronomia, as outras a condicionalismos externos.

Por volta de 1785-1787 encontra-se praticamente reunido, ou em vias disso, todo o acervo instrumental indispensável à efectiva função e actividade astronómica que se pretendiam para um verdadeiro estabelecimento científico tal como os Estatutos estipulavam, nomeadamente a elaboração das efemérides astronómicas. O observatório interino, de carácter provisório e relativamente acanhado, construído para uso das

\footnotetext{
${ }^{7}$ Desde o início da Reforma que o custo das obras foi uma preocupação constante para o Governo e para a Universidade [DRP 1937-1979, v.1 p.71] (em Novembro de 1775 há grandes dificuldades de tesouraria para o pagamento das "Folhas das Obras" [DRP 1937-1979, v.1 p.215]). De facto os livros de despesa referentes às obras do observatório do Castelo fecham as contas no mês de Setembro de 1775 com um custo total de 18879 \$582reis [AUC: Universidade de Coimbra, Administração e Contabilidade, Obras, Observatório Astronómico. Despesas com Obras. Livro I, II, III] - valores efectivamente elevados, a representarem cerca de 15\% do custo global das obras da reforma da Universidade, quando o edifício pouco ia além dos alicerces.

8 "Para o uso interino das Liçōes, e Observações Astronómicas fiz construir hum pequeno Observatório no Terreiro dos Paços das Escolas, o qual tem servido até aqui para o dito fim. [...] Para se não suspender o Exercício das liçōes e Observações Astronómicas enquanto não se acabar o Grande Edifício [observatório do castelo] para elas destinado construir-se no Território dos Paços da Universidade uma Casa térrea para servir de Observatório interino" [Lemos 1777, p.214, 127].
}

${ }^{9}$ Em 1777, segundo John Blankett (1740?-1801), já estava construído [Blankett 1777, p.33]. 
aulas não possuía as necessárias condições de acomodação e uso dos instrumentos que entretanto se haviam adquirido, nem as condiçôes mínimas de observação e trabalho para os astrónomos e calculadores das efemérides. Parece-nos bastante provável que o A.R. de 1-10-1787 assinado pelo Ministro do Reino, D. Tomás Xavier de Lima Visconde de Vila Nova de Cerveira (1727-1800), seja uma consequência directa de sucessivas interpelaçóes de José Monteiro da Rocha (1734-1819) (que para além de professor da cadeira de Astronomia é também Vice-Reitor da Universidade desde 31-7-1786) face à inexistência de um verdadeiro Observatório Astronómico na Universidade capaz de trabalhar no "aditamento da Astronomia"

Há outras razões que poderão também ter contribuído para que esta questão se tenha tornado premente. Uma é a actividade científica da Academia das Ciências de Lisboa (ACL), que inaugura o seu Observatório Astronómico, instalado no Castelo de São Jorge, no início de 1787 (3-1-1787), e que tinha também como objectivo a publicação de umas efemérides 'para utilidade da navegação portuguesa e aumento da Astronomia', colidindo assim directamente com um dos principais objectivos do inexistente Observatório da Universidade ${ }^{11}$; também data destes anos uma série de discussões no seio da ACL sobre a organização e possível levantamento geodésico e cartográfico do Reino. (Lembremos que data também de 1787 a tentativa (A.R. de 16-3-1787) do estabelecimento da Congregação Geral das Ciências conforme os Estatutos haviam estipulado, mas que não se havia concretizado; numa clara reacção da Universidade face ao papel competitivo que a ACL vinha assumindo). Outra das razões é a mudança de Governo. O Governo que se formou (em 24-02-1777) após a subida ao poder da rainha D. Maria I (1734-1816) não contribuiu para dar um novo impulso às obras da Universidade de Coimbra, que vinham do Governo de Pombal. Pelo contrário, faltou empenho e persistência nos trabalhos públicos ao ministro Vila Nova de Cerveira que substituiu Sebastião Carvalho na pasta do Reino. Este Governo, marcado por hesitações e adiamentos, relegaria a questão do Observatório da Universidade para um esquecimento que a partir de 1785 é reavivada por José Monteiro da Rocha - há instrumentos, há recursos humanos; mas não existe um edifício capaz de albergar as diferentes valências indispensáveis a uma efectiva actividade astronómica. Todavia, com a formação de um novo Governo (em 15-12-1788) que vê nomeado José Seabra da Silva (1732-1813), antigo colaborador do Marquês de Pombal na Junta de Providência Literária, para a Secretaria de Estado do Reino, a questão iria, finalmente, resolver-se.

Fazia parte do programa deste novo Governo, movido pela acção de fomento para o território continental, a conclusão de obras que se arrastavam há alguns anos ou de projectos que não tinham sido postos em prática [Martins 2009]. É assim que a partir de 1788 o projecto da construção de um definitivo Observatório Astronómico na Universidade passa a estar verdadeiramente em cima da mesa. Vários projectos são

${ }^{10}$ Nesse A.R. de 1-10-1787 Vila Nova de Cerveira informa o Reitor de que o Observatório da Universidade era para ser efectivamente construído, "Sua Majestade, achando muito justo, e necessário que o Observatório Astronómico, e o Teatro Anatómico se concluam, e acabem, como V. Exa. lhe representou [...]” [DRP 19371979, v.2 pp.177-178].

${ }^{11} \mathrm{O}$ projecto da publicação pela ACL das 'Ephemerides Náuticas, ou Diário Astronómico' (Lisboa, 1788) começara a ser pensado cerca de meia dúzia de anos antes (1781), tendo José Monteiro da Rocha sido sondado pelo Secretário da ACL sobre esse assunto (veja-se [Figueiredo 2011, pp.365-369]). 
então delineados por Manuel Alves Macomboa (?-1815), o arquitecto agora responsável pelas obras universitárias ${ }^{12}$, sob as ordens e consideraçôes de Monteiro da Rocha.

A solução para o definitivo Observatório Astronómico da Universidade de Coimbra (OAUC) passava por fixar a sua localização no topo Sul do Paço das Escolas. Abandonava-se, assim, definitivamente, o longínquo e primitivo Observatório do Castelo projectado por Guilherme Elsden. A concretização da opção de realizar o OAUC no Pátio das Escolas foi muito debatida. No espaço de quatro anos (17881792) são conhecidos quatro projectos arquitectónicos (três deles em menos de meio ano): uma primeira versão em 1788; uma segunda versão em Setembro de 1790; uma terceira em Novembro de 1790; e uma quarta versão em Fevereiro de 1791 e Setembro de 1792 (que corresponde à versão construída). A concretização do projecto do OAUC constituiu um processo riquíssimo de desenho, estando em cima da mesa duas hipóteses (que decorrem, aparentemente, entre 1788 e $1791^{13}$ ) que têm como pontos comuns: o programa de instalações, o carácter permanente do edifício e a sua localização e amarração do edifício ao muro do Terreiro que dá para a rua da Trindade (hoje Rua José Falcão). Estes dados de trabalho, essenciais para se poder projectar, devem ter passado pela Secretaria de Estado do Reino e deviam constituir temas decididos e acordados entre o Estado e a Universidade, ou seja entre José de Seabra da Silva, o Reitor e José Monteiro da Rocha ${ }^{14}$. Em nenhum dos projectos, realizados nesta fase, estes dados estão em causa. Varia isso sim, e isso os distingue, a forma e a disposição volumétrica.

A forma final do edifício - o projecto final do OAUC é aprovado pela Junta da Universidade em 5-2-1791, estando em 1799 concluído o edifício - será constituída por um corpo horizontal com um piso e cobertura plana, e uma torre com três pisos definida a partir do vão central, também com cobertura plana.

${ }^{12}$ Manuel Alves Macomboa, que chega a Coimbra em 1773 como mestre-de-obras, exercerá a partir do ano de 1782 e até 1810 as funçōes de arquitecto das obras da Universidade.

${ }^{13}$ A partir de Setembro de 1790 tudo se passa muito rápido dando a impressão que a decisão tem de ser rapidamente tomada, sendo em pouco tempo realizados três projectos.

${ }^{14}$ Para Seabra de Albuquerque o cerne da questão do projecto do novo OAUC ter-se-á desenvolvido num diálogo mais restrito entre Monteiro da Rocha e Macomboa, em que este vai respondendo de acordo com as hipóteses colocadas pelo Vice-reitor [Albuquerque 1876, p.76]. Há porém outra hipótese a considerar, as propostas do arquitecto e de Monteiro da Rocha por um lado serem tratadas directamente com a Junta da Fazenda da Universidade (Monteiro da Rocha era Vice-Reitor e há documentação que explicita "por mando do vice-reitor"). Outra alternativa, que nos parece mais plausível, é a de ter sido um diálogo directo de Monteiro da Rocha com o ministro que tutelava as obras públicas, José de Seabra da Silva. Segundo o investigador Carlos Martins, muitas obras públicas desta altura conhecem vários projectos e alternativas e o processo vai passando directamente pelo ministro, que vai dando instruçôes caso a caso (as alternativas normalmente vêm da equipa projectista mas passa tudo pelo ministro). Assim no caso do projecto do OAUC estamos em crer que este terá sido fruto de Monteiro da Rocha em diálogo com o Ministro e Macomboa a desenhar e a fazer o que o primeiro manda. (Monteiro da Rocha é referido explicitamente não só nas próprias plantas e desenhos dos projectos do OAUC mas em vários outros documentos justificativos de despesas referentes à obra; note-se que o Aviso Régio de 23-1-1778 autorizava a Junta da Fazenda a dispor sem prévia licença régia de $400 \$ 000$ reis anuais para despesas de obras). 


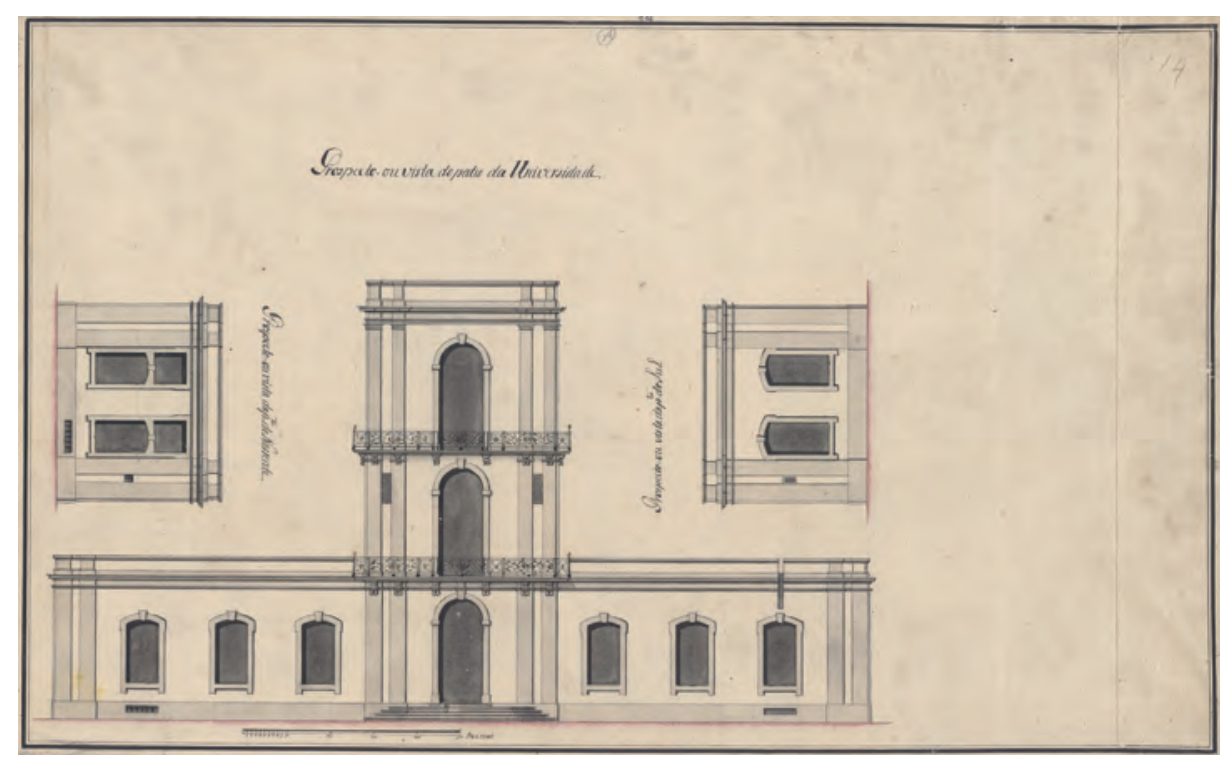

Figura 5 - Prospecto ou vista do pátio a Universidade. [BGUC Ms. 3377-44]

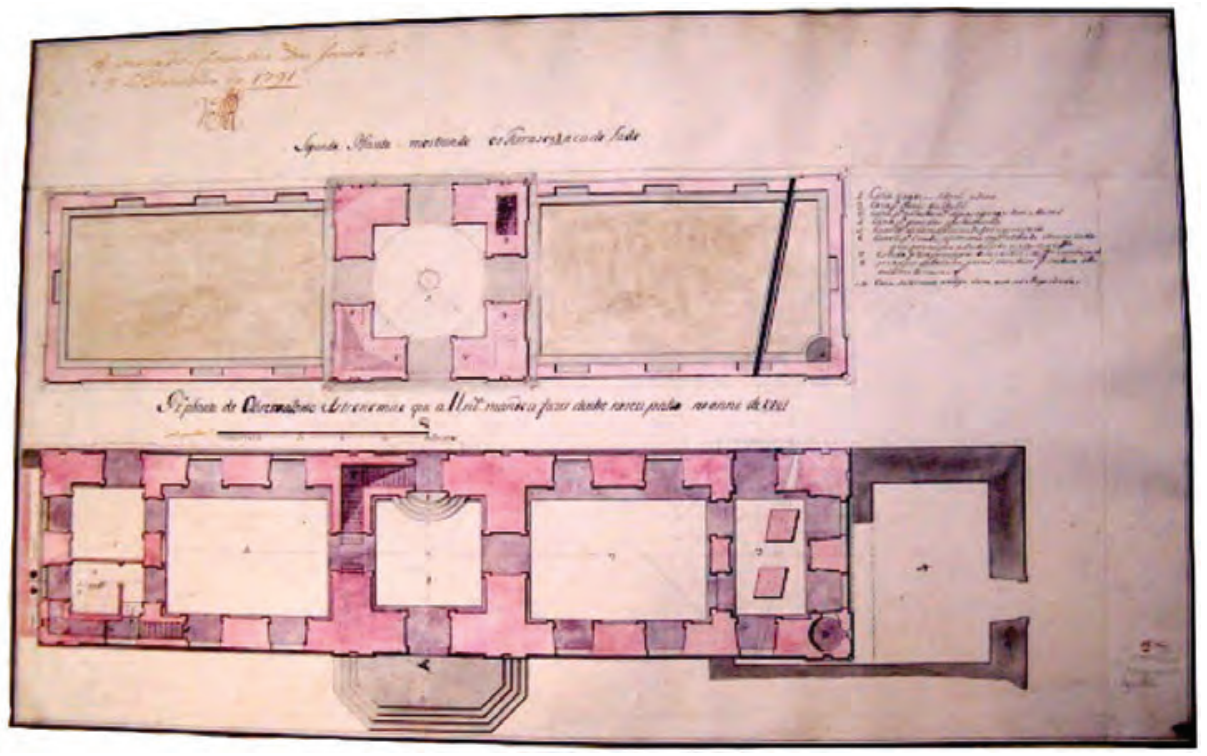

Figura 6 - Planta do Observatório Astronómico que a Universidade mandou fazer dentro no seu pátio no anno de 1791. [BGUC Ms. 3377-44] 


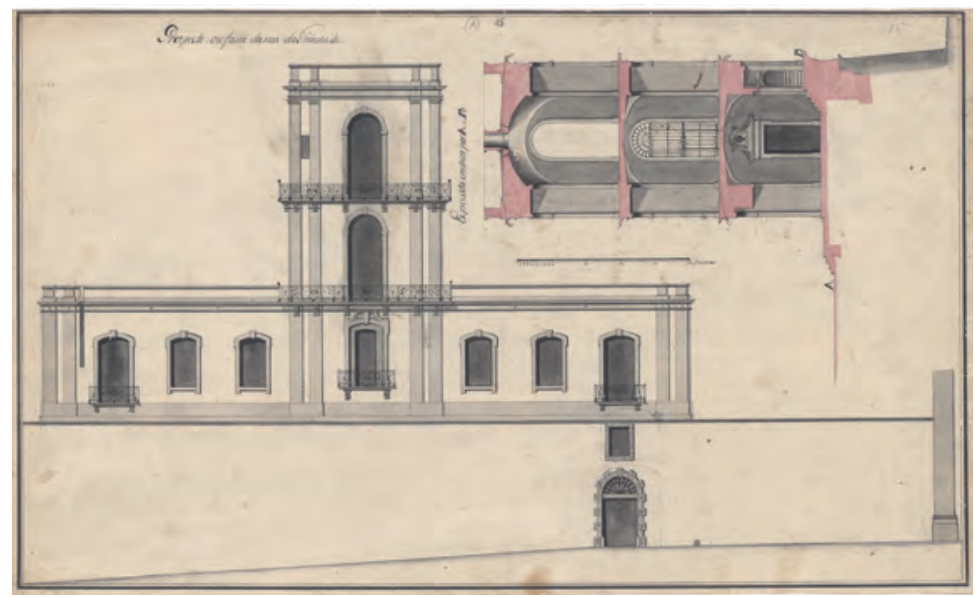

Figura 7 - Prospecto ou fasia da rua da Trindade e Expecato emtrior por A B. [BGUC Ms. 3377-45]

Este edifício é um bom exemplo do desfasamento entre as ambições iniciais da Reforma Pombalina e a nova realidade. Pensado no seu início como um edifício destacado de todos os estabelecimentos científicos, o Observatório Astronómico da Universidade de Coimbra acabava no mais modesto de todos eles ${ }^{15}$. Abdicava-se da carga simbólica e da função urbana iniciais e concentrava-se a atenção na criação de um estabelecimento astronómico [Martins \& Figueiredo 2008].

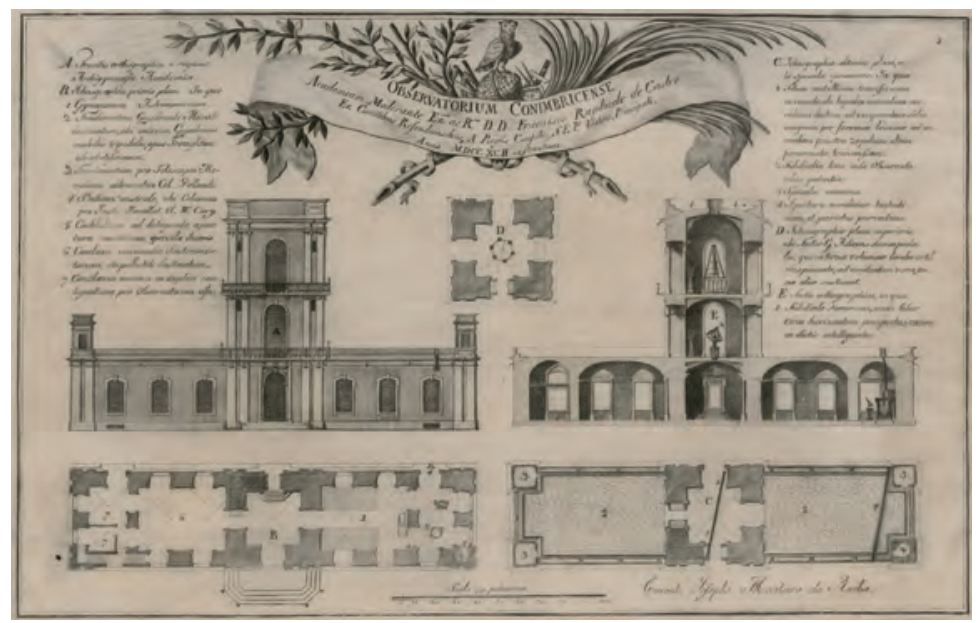

Figura 8 - Observatorium Conimbricense Academian Moderante Ex.mo ac Rmo D. D. Francisco Raphaele de Castro Ex Comitibus Resendiensibus, A Regiis Consiliis, S. E. P. Lisbon principali, Anno M.DCC.XCII exstructumicense (1792). Manuel Alves Macomboa. [OAUC G-2]

${ }^{15}$ A $1 .^{a}$ versão do Observatório do Castelo compreendia um edifício com uma frente de $49 \mathrm{~m}$ e uma altura (pela torre mais alta) de $31 \mathrm{~m}$; a $2 .{ }^{\mathrm{a}}$ versão compreendia um edifício de frente $58 \mathrm{~m}$ e uma altura total (do solo ao topo da torre) de $37 \mathrm{~m}$. O OAUC construído no Pátio tinha de frente $41 \mathrm{~m}$ e uma altura total de $24 \mathrm{~m}$. 


\section{O Acervo Instrumental e o Programa Astronómico do OAUC}

A real prática astronómica de um observatório está, obviamente, ligada ao acervo instrumental que este possui, ou, para sermos mais precisos, devemos afirmar que é o acervo instrumental de um observatório que dita o seu programa observacional; ou seja, a sua real e efectiva prática astronómica. Como afirmámos um dos motivos que leva, nos finais da década de 1780, à resolução do problema da inexistência, na Universidade, de um verdadeiro Observatório Astronómico tal qual os Estatutos estabeleciam, é o património instrumental que ao longo dos anos foi sendo adquirido e cujo núcleo fundamental se encontrava por essa altura praticamente reunido. O observatório interino se servia para que "os estudantes [pudessem] nele tomar as Liçôes da Astronomia Prática”, não servia com certeza para que os professores e os astrónomos nele trabalhassem. Este edifício provisório não reunia nem as necessárias condiçôes materiais para uma verdadeira prática observacional, nem, pelas suas pequenas dimensóes, as condiçôes suficientes para uma efectiva e desejada investigação científica. Servia quando muito, e possivelmente com várias condicionantes, para a guarda de alguns dos instrumentos astronómicos. Porém os sucessivos projectos para o edifício definitivo, que a partir de 1788 vão sendo delineados, contemplam todos os requisitos de um verdadeiro estabelecimento científico: espaços específicos para arrumação dos instrumentos, bem como para a sua instalação definitiva em salas e locais próprios para observação. O definitivo OAUC (1799) organiza-se em vários espaços diferenciados: salas de aula, salas de observação, gabinetes, salas de instrumentos (nas plantas dos projectos (1790-1792) especifica-se mesmo as salas do Mural, do Sector e do Zénite), biblioteca, quarto de dormir e sala de jantar. A organização do espaço do OAUC responde às exigências práticas da própria praxe observacional, ou seja o espaço de observação disciplina o próprio espaço no qual se inscreve.

O grande programa astronómico dos finais do século XVIII e primeiras décadas do XIX concentra-se em torno da mecânica celeste, caracteriza-se por uma constante busca de precisão na posição dos astros, principalmente os do sistema solar e das estrelas, de modo a contribuir para a melhoria da teoria newtoniana e das ferramentas matemáticas que compreendem os fenómenos celestes ${ }^{16}$. Neste processo contínuo - de desenvolvimento dos métodos instrumentais de observação, redução das observações e refinamento da teoria -, a astronomia prática desenvolve-se essencialmente em torno da medição angular das ascensões rectas e das declinações dos astros que passam no meridiano dos observatórios. A astronomia observacional não é por si própria investigação mas fornece, isso sim, dados observacionais para o astrónomo teórico. Esta necessidade de dados leva a que os observatórios se apetrechem com instrumentos cada vez mais precisos ocupando os telescópios meridianos, os instrumentos de passagens, os sectores, os telescópios reflectores e os quadrantes murais o cerne instrumental de qualquer observatório bem apetrechado da época. A grande preocupação do astrónomo do século XVIII é a recolha sistemática e precisa das posi-

16 "L’Astronomie, considérée de la manière la plus générale, est un grande problème de Mécanique, dont les éléments des mouvements célestes sont les arbitraires; sa solution dépend à la fois de l'exactitude des observations et de la perfection de l'analyse, et il importe extrêmement d'en bannir tout empirisme et de la réduire à n'emprunter de l'observations que les données indispensables" [Laplace 1878-82, v.1 p.i]. 
ções dos astros, principalmente dos corpos dos sistema solar e das posições estelares. O essencial para o astrónomo é medir e essas medições exigem instrumentos cada vez mais precisos (os telescópios e lunetas por si só não o fazem). A astronomia prática tornou-se a rotina principal de qualquer observatório oitocentista, uma rotina que se renovava continuamente numa procura de uma maior exactidão observacional e na busca de novos métodos de instrumentação e observação. Este programa foi a base de um progresso triunfante para a ciência astronómica e esteve na base do desenvolvimento de uma verdadeira indústria de instrumentos astronómicos, onde os fabricantes ingleses passam a ocupar, a partir da década de 1720 um lugar de destaque, consequência dessa demanda de exactidão e precisão.

O núcleo duro instrumental de um típico observatório do século XVIII ancorava-se então num conjunto de meia dúzia de instrumentos imprescindíveis ao desenvolvimento da astronomia meridiana. No centro deste grupo está o quadrante mural que se torna a quintessência do observatório oitocentista [Turner 2002] ${ }^{17}$. Juntamente com o quadrante mural, outros instrumentos compóem esse núcleo essencial de instrumentos muito precisos. No verbete "Observatoire", que Lalande escreve para a Encyclopédie Méthodique, lá estão especificados esses instrumentos indispensáveis: "un quart de cercle mobile [...], une lunette méridienne [...], un mural [...], une bonne lunette achromatique de 3 à 4 pieds, montée sur un pied parallactique [...], pendule \& le compteur" [Encyclopédie Méthodique (mat.) 1784-89, t.II p.481] ${ }^{18}$. Também o astrónomo Antoine Darquier (1718-1802), director do Observatório de Toulouse, especifica quais os instrumentos necessários para habilitar um observatório para um efectivo estudo dos céus, "[Avec les instruments ci-dessus détaillés, un observateur exercé \& laborieux pourra faire beaucoup d'observations utiles]: $1 .^{\circ}$ un quart de cercle de cuivre $[\ldots] ; 2 .^{\circ}$ un bon instrument de passages de deux pieds $[\ldots] ; 3^{\circ}$ une bonne pendule à secondes, à verge simple ou composée [...]; $4^{\circ}$ un compteur, vous savez que c'est un mouvement de pendule simple qui marque les minutes, se sonne les secondes, $5^{\circ}$ une lunette ordinaire de deux pieds [...]; $6^{\circ}$ un petit quart de cercle de 18 à 20 pouces de rayon [...]; $7^{\circ}$ une lunette de 7 à 8 pieds, ou un télescope à réflexion de 18 pouces au moins" [Darquier 1786, pp.5-7].

O núcleo instrumental fundamental do OAUC está bem identificado na planta final de 1792: "Observatorio Conimbricense (1792)" (fig.9), onde se mostra a localização específica das salas para esses instrumentos: quadrante mural - "Fundamentum Quadranti Murali destinatum ubi interim Quadrans mobilis tripedalis, opus Troughtoni absolutissimum"; instrumento de passagens - "Fuandamentum pro Telescopio Meridiano acromático Cel. Dollondi”; luneta paralática - “"Podium australe, ubi Columna pro Instr. Parallat. cl. W. Cary"; sector - "Ichnographia plani superioris,

${ }^{17}$ Este instrumento, que já ocupa, é certo, nos grandes observatórios árabes da época medieval, mais tarde no observatório de Tycho Brahe (1546-1601) e depois no de Greenwich com Flamsteed um papel de relevo, assume no século XVIII uma primazia tornando-se o primeiro de uma nova classe de instrumentos muito precisos. É a partir do quadrante mural de 8 pés feito por George Graham (1673-1751), em 1725, para uso de Halley (1656-1742) no Observatório de Greenwich, que o modelo se desenvolve, tornando-se então a partir daí quase omnipresente nos Observatórios (veja-se [Learner 1981, pp.52-72]).

${ }^{18}$ E são também estes os instrumentos que Lalande dedica dois capítulos no seu Astronomie (1771): "des instruments d'astronomie (Cap. XIII)" [Lalande 1771-81, v.2 pp.722-830] e "de l'usage des instruments \& de la pratique des Observations (cap. XIV)" [Lalande 1771-81, v.3 pp.1-82]. 
ubi Sector G. Adams decempedalis, quem ternae columnae limbo ortu respiciente, ad occidentem verso, ternae aliae sustinent"; bem como três pêndulas e ainda pequenos telescópios - "speculae minores". O Observatório de Coimbra não chegou a ter um quadrante mural fixo mas tinha quartos-de-círculo, onde se destaca o quadrante portátil de Troughton ${ }^{19}$. O quarto-de-círculo, munido de micrómetro ou retículo romboidal, acabará por ser o instrumento mais versátil e de mais amplo uso nos observatórios, suplantando o quadrante Mural que é difícil de fabricar, difícil de instalar e acima de tudo muito caro, sendo incomportável para o orçamento da maior parte dos Observatórios ${ }^{20}$.

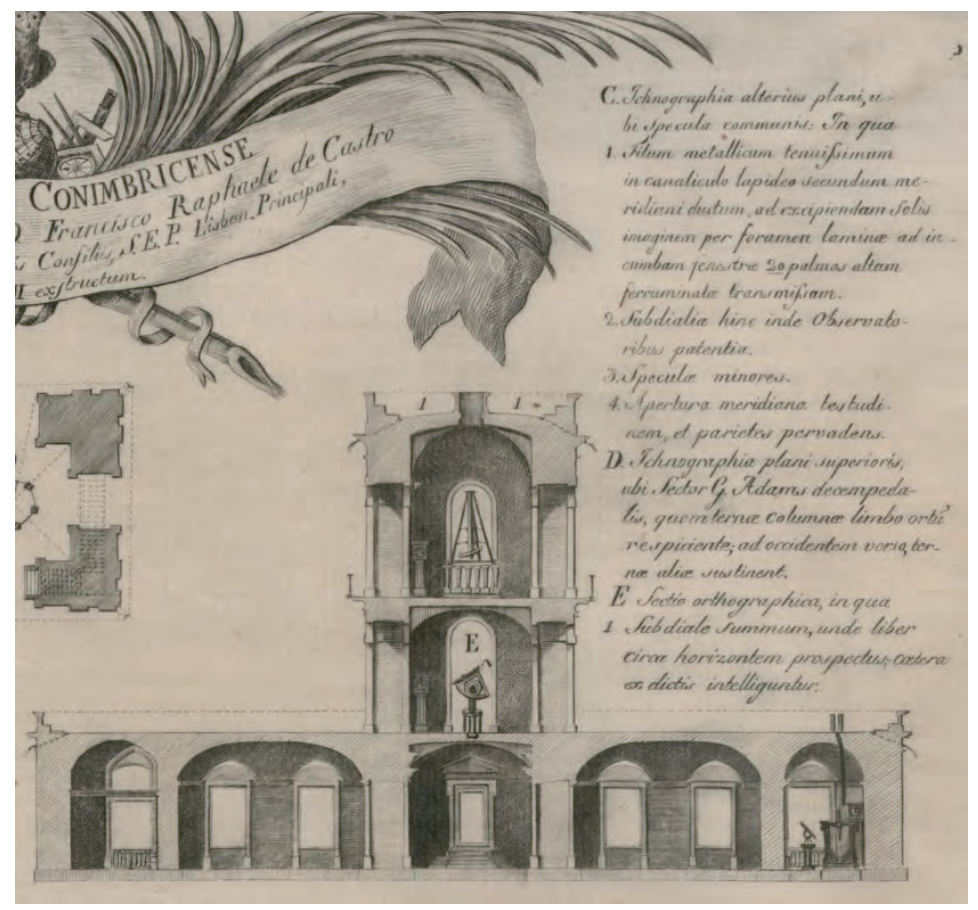

Figura 9 - Pormenor da planta [fig. 8] do OAUC

- «Observatorium Conimbricense [...1792]» [OAUC G-2].

Como se vê o OAUC possuía os principais instrumentos que constituem no século XVIII o cerne instrumental de um completo observatório astronómico, e por isso fundamentais para o estabelecimento de um efectivo programa observacional astrométrico ${ }^{21}$. Efectivamente o arsenal instrumental do OAUC coloca-o a par dos bons

${ }^{19}$ Numa das plantas para o Observatório do Castelo há uma com um quadrante: "Risco do Quadrante Mural copiado do que se acha no Real Observatório da Vila de Greenwich, com a descrição da construção, uso dele em observações astronómicas" [BNRJ Inv. 1.093.803AA n.X].

${ }^{20}$ Vejam-se [Turner 2002] e [Brooks 1991].

${ }^{21}$ São também estes os instrumentos que os Estatutos de 1772 já especificam como os que deveriam provir a "Colecção de bons Instrumentos do Observatório da Universidade": "um Mural, feito por algum dos melhores Artífices de Europa; e um bom sortimento de Quadrantes; de Sectantes de diferentes grandezas; de Micrómetros; 
observatórios europeus desta época e o seu programa científico (delineado na C.R. de 4-12-1799, \$\$.7-10) sintoniza-o em absoluto com o programa da ciência astronómica dos grandes observatórios internacionais da altura ${ }^{22}$.

\section{A Biblioteca do OAUC}

O trabalho astronómico de qualidade faz-se não só com bons instrumentos mas também com acesso a livros e a obras de referência ${ }^{23}$. Cientes disto, também os responsáveis pela construção do OAUC lhe prevêem uma 'casa de livraria'. Apesar da planta do OAUC ('Observatorio Conimbricense (1792' [OAUC G-006]) não apontar especificamente essa divisão, a verdade é que tanto o inventário de 1810 [OAUC Inventário 1810] como o de 1824 [OAUC Inventário 1824] referem a existência de uma biblioteca no Observatório, elencando as obras aí existentes ${ }^{24}$.

Através dos dois inventários é possível perceber que entre 1810 e 1824 a biblioteca foi aumentada substancialmente, possuindo um conjunto muito significativo de títulos. No inventário de 1810 constam, entre livros, mapas e cartas celestes, 50 títulos, no de 1824 listam-se 146 títulos.

Estão presentes, no que diz respeito aos livros de astronomia e de instrumentos, autores (maioritariamente franceses) como: Lacaille, Lalande, Delambre, Pingré, Bailly, Bouguer, Borda, Laplace, Bird, Berthoud, entre outros. Possuía as mais representativas efemérides e tabelas astronómicas estrangeiras: as francesas, 'Connaissance des Temps' e as 'Ephemerides des Mouvements Celestes'; o 'Nautical Almanak' inglês; as efemérides de Berlim, 'Berliner Astronomische Jahrbuch'; as do Observatório de Brera (Milão), 'Ephemeridi Astronomi di Milano'; as espanholas do Observatório de Cádiz, 'Almanaque náutico y efemérides astronómicas do Observatório Real de Cádiz'; bem como as portuguesas da ACL, 'Efemerides Náuticas, ou Diário Astronómico' e, evidentemente, as suas próprias efemérides, 'Ephemerides Astronomicas calculadas para o meridiano de Coimbra'. Também possuía as de Weimar, editadas por Franz Xaver von Zach (1754-1832), 'Allgemeine Geographische Ephemeriden'. No que diz respeito a tabelas astronómicas constam nos inventários: as de Halley (1656-1742); de Tobias Mayer (1723-1762); de Lalande, Tables astronomiques pour servir a la trosieme edition de l'Astronomie (Paris, 1792); as de Alexis Bouvard (1767-

de instrumentos de Passagens; de Máquinas Paraláticas; de Telescópios; de Níveis; de Pêndulas [...] e de tudo o mais necessário a um Observatório, em que se há-de trabalhar eficaz, e constantemente no Exercício das Observações, e progresso da Astronomia” [Estatutos 1772, v.3 p.214].

${ }^{22}$ Adrien Balbi em visita (1808) ao OAUC afirma que para além de bem construído e bem situado, "il était aussi trés-bien fourni d'instrumens" [Balbi 1822, v.2 p.95]; também Lalande já o havia elogiado: "Nous avons reçu encore une description de l'Observatoire de Coimbre, par laquelle on voit qu'il y a des instrumens considérables; un secteur de dix pieds, une lunette méridienne de cinq pieds, un quart-de-cercle de trois pieds et demi, divisé à Londres par Troughton.” [Lalande 1803, pp.871-872].

${ }^{23}$ Darquier adverte que todo o astrónomo deve ter acesso a bons livros teóricos e ele próprio, à semelhança de outros observatórios europeus, possuía no de Toulouse uma biblioteca bem fornecida: "pour la théorie, qu’il faut toujours faire marcher de front, vous avez dans ma bibliothèque tout ce que vous pouvez désirer à cet égard: les ouvrages des MM. de la Caille, le Monnier, de la Lande, \&c. vous offrent des secours bien plus puissants que tous ceux que vous pourriez attendre de moi.» [Darquier 1786, p.2].

24 "Gabinete dos livros" e "livraria”, assim é designada respectivamente nos inventários de 1810 e 1824. 
-1843), Tables Astronomiques de Júpiter, de Saturne et d'Uranus (Bureau des Longitudes) (Paris, 1821); as de J. B. J. Delambre (1749-1822) e de Tobias Bürg (17661835), Tables Astronomiques (Bureau des Longitudes) (Paris, 1806); entre outras. Também não falta a importante publicação editada por von Zach, as Monatliche Correspondenz. Também possuía as famosas publicaçôes das observações do Observatório de Greenwich, feitas pelos astrónomos reais, James Bradley (1693-1762), Maskelyne (1732-1811) e John Pond (1767-1836). São também várias as cartas celestes possuídas: o famoso atlas de John Flamsteed (1646-1719) - Historia Coelestis Britannica (Londres, 1725) -, bem como a tradução portuguesa feita por Francisco António Ciera (1763-1814) e Custódio Gomes Villas-Boas (1744-1808) e publicada pela Imprensa Régia, em 1804. Da Uranographia (1801) de J. Elert Bode (17471826) possuía encaixilhadas várias cartas celestes - "Colecção cartas celestes de Bode (encaixilhadas)».

\section{A Actividade Lectiva e Científica do OAUC}

\section{A criação da cadeira de Astronomia Prática (1801) e as aulas práticas}

No que concerne às aulas de astronomia (na sua componente prática) é evidente que o estabelecimento do OAUC (1799) traz também mudanças significativas. A partir de 1799 o ensino da disciplina de Astronomia sofre uma significativa mudança, cerca de 16 meses depois da entrada em funcionamento do OAUC procede-se a uma reforma curricular do $4 .^{\circ}$ ano deixando a Astronomia de ser ensinada numa única cadeira e passando a sê-lo em duas. Pela C.R. de 1-4-1801 a primitiva cadeira de Astronomia é desdobrada em duas cadeiras autónomas, cada uma com um professor respectivo: uma de Astronomia Teórica e outra de Astronomia Prática [AUC IV-1. ${ }^{a}$ E-8-3-4]. A justificação desta reestruturação é apresentada logo no preâmbulo do referido documento régio: "visto que pela sua vastidão não podem ser compreendidos nas lições delas com a extensão e profundidade que convém”. Imponham-se novos desafios à Faculdade de Matemática e ao ensino de algumas matérias que esta reestruturação tenta resolver ${ }^{25}$.

A criação da cadeira de Astronomia Prática é, no nosso entender, uma consequência directa da própria criação do OAUC e da necessidade que se lhe impõe de começar a desenvolver uma sólida actividade científica de modo a cooperar com os trabalhos dos Observatórios europeus congéneres. Pretendia-se que os poucos alunos que chegavam ao $4 .^{\circ}$ ano do curso adquirissem um sólido conhecimento e formação astronómica, para os empregar mais tarde, se isso fosse seu desejo, no trabalho teórico e prático do $\mathrm{OAUC}^{26}$. Ficava assim definido que na cadeira de Astronomia Teórica se faria o estudo da mecânica celeste, mencionando-se explicitamente o estudo dos

${ }^{25}$ Esta reestruturação de 1801 também introduz uma outra cadeira no currículo do "curso mathematico" a cadeira de Hidráulica, cuja criação foi fortemente motivada pelos desafios que se colocavam com a obra do encanamento do rio Mondego para a qual o Governo havia solicitado parecer científico à própria Faculdade [Figueiredo 2011, pp.190-196].

${ }^{26}$ Embora segundo o novo regulamento do OAUC as aulas práticas de Astronomia devessem decorrer de modo a não interferirem com a actividade principal dos astrónomos, os melhores alunos, sob supervisão, podiam 
"últimos descobrimentos das desigualdades seculares", matéria fundamental para o suporte teórico das tabelas e efemérides astronómicas e que Laplace (1749-1827) havia tratado no $2 .^{\circ}$ volume do seu Mécanique Celeste (1799) e que depois desenvolveria e aprofundaria no $3 .^{\circ}$ volume (1802). Na cadeira de Astronomia Prática tratar-se-ia da teoria e uso dos instrumentos astronómicos, bem como dos cálculos e métodos das reduções das observaçōes e especialmente "do cálculo das Tábuas Astronómicas em todas as suas partes" [C.R. 1-4-1801]. No que diz respeito ao horário das aulas, a Carta Régia deixava-o à consideração do Reitor ${ }^{27}$.

No que diz respeito aos compêndios a mesma carta régia mandava que se fizessem "[desde] logo suplementos aos Compêndios até agora adoptados, enquanto não se formarem outros mais completos ao nível dos conhecimentos actuais". Na Astronomia Teórica seria então usado o Mécanique Celeste de Laplace e na de Astronomia Prática continuaria a ser adoptado, cerca de 20 anos mais, o compêndio de Lacaille (1713-1762) (só em 1823 se adoptará o compêndio de Jean-B. Biot (1774-1862) ${ }^{28}$ ). Sobre as efectivas aulas práticas, observações e cálculos astronómicos, não se encontra, infelizmente, suporte documental algum que no-lo revele com pormenor. Porém não seriam muito distintos dos trabalhos e observaçôes astronómicas que os alunos da Academia Real da Marinha efectuavam no seu Observatório da Marinha ${ }^{29}$, pois tratam-se de observaçôes e cálculos fundamentais para qualquer futuro astrónomo e piloto da marinha, e que compreendiam: determinaçôes da altura do Sol; determinação das suas ascensões rectas e declinações; cálculo de distâncias de estrelas ao Sol; alinhamento e ocultações de estrelas; determinação dos instantes de emersões e imersōes dos eclipses dos satélites de Júpiter; determinação da latitude e longitude do observatório; rectificação de instrumentos e regulação das pêndulas ${ }^{30}$.

participar nas actividades observacionais quotidianas do OAUC, com o objectivo expresso de "nesse exercício se habilitarem melhor para serem providos nos lugares, que vagarem".

${ }^{27}$ Segundo parece reservou-se inicialmente o horário das $9 \mathrm{~h}: 30 \mathrm{~m}-11 \mathrm{~h}: 30 \mathrm{~m}$ para a cadeira de Astronomia Prática e o das $15 \mathrm{~h}: 30 \mathrm{~m}-17 \mathrm{~h}: 30 \mathrm{~m}$ para a de Astronomia Teórica, mas este seria mudado a pedido dos alunos: "Representam a V. Exa. os Estudantes do $4 .^{\circ}$ ano Matemático cujo número é composto de um representante e cinco voluntários que tendo duas aulas uma de Astronomia Prática que principia à nove horas e meia, e acaba às onze da manhã, e outra teórica desde as três e meia até às cinco da tarde devendo para cumprir qualquer delas fazerem uma séria aplicação para que o quantas muitas vezes não chega o tempo, gastando-se uma parte dele nas vindas e idas ao Real Observatório, lugar das mesmas Aulas, e sendo o meio mais próprio para evitar isto a mudança da Aula de Astronomia Teórica para as onze e meia da manhã, tempo em que finaliza a de Astronomia Prática; e como para isto obtiveram o consentimento do respectivo Lente, que atendendo à evidente comodidade dos seus Alunos anuiu dar a esta hora as suas Liçôes, e tem disto esta Aula, como modernamente criada não tem hora senão a que V. Ex. ${ }^{a}$ lhe apresar, por isso pede a V. Ex. ${ }^{a}$ se digne transferir a Aula de Astronomia Teórica para a hora em que finalizar a de Astronomia Prática [s.d.]” [BGUC Ms. 2530, n.o.36].

${ }^{28}$ Para a cadeira de Astronomia foram adoptados desde logo (em 1772): o Leçons Elémentaires d'Astronomie Géometrique et Physique (Paris, 1746) de Lacaille, e o Astronomie (1764) de Lalande [Figueiredo 2011, pp.8286, 131-136].

${ }^{29}$ A Academia Real da Marinha, fundada em 1779, tinha como objectivo formar os futuros oficiais da Armada e para o efeito ministrava um curso de três anos, onde se ensinavam matérias de matemáticas puras e aplicadas, astronomia e náutica (trigonometria esférica, navegação teórica e prática). O Observatório Real da Marinha foi criado em 1798, "destinado à prática de instrumentos de observação astronómica como meio de preparação dos futuros oficiais da Marinha” [Reis 2009, p.30].

30 "Diário de exercícios práticos que se tiveram no Real Observatório da Marinha" [ANB Códice 807 NP], com a informação remetida pelo Inspector do Observatório da Marinha, Pedro Mendonça de Moura (1745-?), ao 
O ponto sétimo da C. R. de 4-12-1799 fixa com precisão o objectivo maior de toda a actividade científica do OAUC: a publicação das Efemérides Astronómicas - "Para o Meridiano do Observatório, e para uso dele (assim como se pratica nos mais célebres da Europa) se calculará a Ephemeride Astronómica, a qual igualmente possa servir para uso da Navegação Portuguesa e que não será, reduzida e copiada do Almanac do Observatório de Greenwich, nem de outro algum, mas calculada imediatamente sobre as Tábuas Astronómicas". O mesmo documento estabelece ainda que se deveria começar "logo pelo trabalho da que há-de servir no ano de 1804 e depois dela nas dos seguintes" ${ }^{1}$. O cálculo, a elaboração e a publicação das "Ephemerides Astronomicas calculadas para o meridiano do Observatório Real da Universidade de Coimbra para uso do mesmo Observatório, e para uso da Navegação Portuguesa' (EAOAUC) serão a partir do primeiro momento o trabalho maior e a imagem de marca do OAUC durante todo o século XIX ${ }^{32}$.



Figura $10-1 .^{\circ}$ volume (1803) das 'Ephemerides Astronomicas' do OAUC.

Ministro da Marinha, D. Rodrigo de Sousa Coutinho (1745-1812), informando-o sobre o progresso das aulas e outros assuntos da Academia da Marinha.

${ }^{31} \mathrm{O}$ mesmo documento isentava de qualquer licença as publicaçôes do OAUC: "E tanto a Ephemeride, como as Colecções de Observaçōes Astronómicas, Tábuas, e Explicaçōes delas, sendo assinadas pelo Director, e com a licença do Reitor, serão impressas na Oficina da Universidade, como de ordem Minha, sem dependerem de outra licença."

${ }^{32}$ As 'Ephemerides Astronomicas' serão publicadas ininterruptamente até ao ano de 1827 (volume 19), com as efemérides astronómicas para 1828 [EAOAUC (1828) 1827, v.19]. Segue-se um período de 13 anos em que nenhum volume é publicado, retomando-se a publicação em 1840 com as efemérides para os anos de 1841 e 1842 [EAOAUC (1841-42) 1840, v.20]. 
As EAOAUC foram idealizadas e criadas por José Monteiro da Rocha, adoptando desde o $1 .^{\circ}$ volume (1803) algumas particularidades face às suas congéneres europeias (Connaissance des Temps (Paris), Nautical Almanac (Londres) e Berliner Astronomisches Jahrbuch (Berlim)); eram calculadas em relação ao Sol médio e não ao Sol verdadeiro, usavam a medida dos $3600^{\circ}$ e não a amplamente utilizada unidade de signo, e adoptaram um método de interpolação especial para calcular as efemérides da Lua. Estas inovações seriam alvo de críticas positivas por parte de alguns dos principais astrónomos da época (p. ex. Jean-Baptiste-J. Delambre (1749-1822) e John Pond (1767-1836)), que as incorporariam mais tarde nas suas publicaçōes. À semelhança do Connaissance des Temps e do Nautical Almanac também as Ephemerides do OAUC publicaram (1803-1813) em alguns volumes artigos científicos, bem como diversas tabelas. Esses trabalhos, da responsabilidade científica de Monteiro da Rocha, estão relacionados, de uma maneira ou de outra, com o próprio cálculo, elaboração e uso das Efemérides.

\section{A Organização das Efemérides Astronómicas do OAUC}

O 1. ${ }^{\circ}$ volume (1803) compreende o seguinte:

- «Regulamento do Observatório Real da Universidade de Coimbra» (C. R. de 4-12-1799) (voltaria a ser impresso no volume 11 (1814);

- Épocas principais; sinais e abreviaturas; eclipses do ano 1804 e errata;

- ‘Folhas Mensais', com as efemérides correspondentes a cada um dos meses do ano;

- «Taboas Auxiliares para uso destas Efemérides, e para o cálculo das Longitudes» (22 tabelas);

- Catálogo das estrelas principais reduzidas ao primeiro de Janeiro de 1805;

- «Explicação e uso dos Artigos principais destas Ephemerides e das Taboas auxiliares publicadas neste volume»;

- «Cálculo das Longitudes»;

- "Cálculo dos Eclipses» e "Aplicação do método antecedente ao cálculo dos eclipses da Lua»;

- «Táboa do encurtamento dos semidiâmetros do Sol, e da Lua, causado pela Refracção»;

- «Taboas de Marte para o Meridiano do Observatório Real da Universidade de Coimbra».

Os volumes seguintes seguem genericamente a mesma organização das matérias (diferindo no conteúdo dos artigos científicos). A partir do volume III (1805) passam a ser incluídas duas extensas tabelas, uma com informação sobre longitudes de vários lugares da Terra - «Tábua da diferença dos meridianos dos Lugares principais da Terra, relativamente ao Observatório da Universidade de Coimbra com as suas Latitudes, ou Alturas do Pólo» -, e outra com informação geográfica de vários portos e locais da orla costeira de vários mares e oceanos do globo - «Tábua Cosmográfica dos Portos, Cabos, Ilhas, e Lugares das Costas Marítimas do Orbe terráqueo, pela ordem das mesmas Costas com as suas Latitudes, e Longitudes contadas do meridiano do Observatório da Universidade de Coimbra». São também publicadas algumas observações astronómicas realizadas tanto no OAUC, como noutros observatórios e locais. A partir do volume 9 (1812) passa a ser incluída a lista dos astrónomos responsáveis pelos cálculos, «Pessoas efectivamente empregadas nos trabalhos das Ephemerides, com a declaração dos cálculos pertencentes a cada um». 
As efemérides astronómicas são calculadas a partir de tabelas astronómicas e a construção destas últimas depende da íntima conjugação das previsões teóricas com os dados observacionais, dos quais depende a identificação das irregularidades dos movimentos dos astros que a própria teoria prevê. Nos finais do século XVIII as tabelas astronómicas mais precisas haviam sido publicadas por Lalande na 3. ${ }^{\mathrm{a}}$ edição do seu Astronomie (1792). As primeiras EAOAUC são calculadas usando precisamente estas "Tables Astronomiques", de Lalande, exceptuando as efemérides de Marte que são calculadas usando umas tabelas elaboradas pelo próprio Monteiro da Rocha (e publicadas no primeiro volume das próprias EAOAUC - "Taboas de Marte para o Meridiano do Observatório Real da Universidade" de (1803). Em 1806 o Bureau des Longitudes francês publica umas tabelas do Sol e da Lua da autoria de Delambre e de Johann Tobias Bürg (1766-1835) [Delambre \& Bürg 1806]; estas tabelas passarão a servir de base para o cálculo das posições do Sol e da Lua das EAOAUC (já as posições dos outros corpos continuam a ser calculadas pelas tabelas de Lalande).

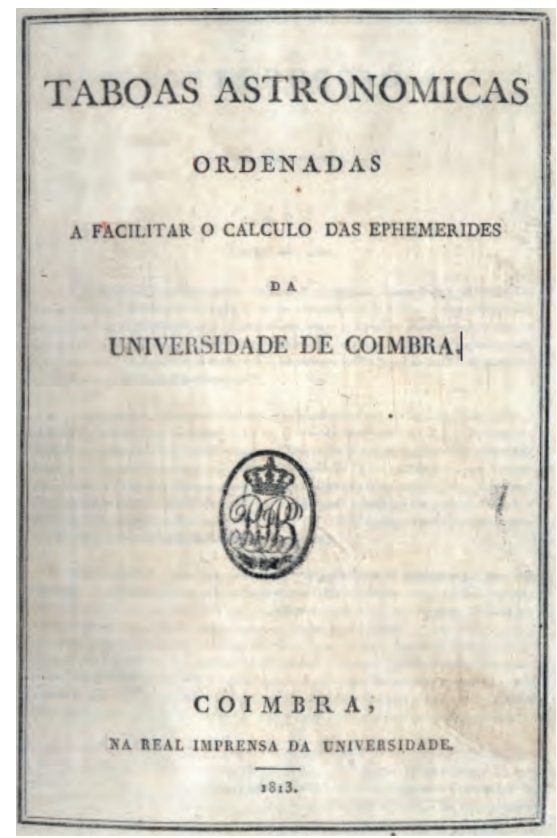

Figura 11 - Taboas Astronomicas (1813), de José Monteiro da Rocha.

Em 1813 Monteiro da Rocha publica as suas próprias tabelas astronómicas, intituladas: "Taboas Astronómicas ordenadas a facilitar o Calculo das Ephemerides da Universidade de Coimbra" (Coimbra, 1813). Estas "Taboas" compreendem tabelas do Sol, da Lua e dos planetas e passarão a constituir, a partir do volume 11 (1814) a base de cálculo das EAOAUC: "Os lugares do Sol e da Lua, tanto para o ano de 1815 e 1816, foram já calculados pelas Novas Taboas Astronomicas, reduzidas ao Meridiano do Observatório pelo seu Director, o qual, conservando-lhes toda a exactidão, as dispôs e ordenou de uma forma engenhosa, e admirável, que as torna muito cómodas para os calculadores; e por isso muito recomendáveis. Os lugares dos Planetas para o 
ano de 1815 foram calculados pelas antigas Taboas, em razão de não estarem impressas ainda as novas, que lhes eram relativas; não assim para 1816, em que já todas vão calculadas pelas Novas» [EAOAUC (1814-15) 1814, v.11 `Advertência)].

As restantes EAOUAC da $1 .^{a}$ série serão todas elas calculadas com base nestas tábuas de Monteiro da Rocha, com excepção do volume para o ano de 1828 [EAOAUC (1828) 1827, v.19] em as efemérides do planeta Júpiter são calculadas pelas tabelas de Delambre publicadas em 1817. Aquando do recomeço da 2. a série, em 1840, os lugares do Sol e da Lua continuam a ser calculados pelas tabelas de Monteiro da Rocha, passando porém a ser usadas as tabelas de Marie Charles Damoiseau de Monfort (1768-1846) para os cálculos dos lugares do planeta Júpiter e as de Alexis Bouvard (1767-1843) para os lugares de Saturno e Úrano. A partir das Ephemerides Astronómicas para 1847 [EAOAUC (1847) 1845] as efemérides da Lua passam a ser calculadas pelas tabelas de Johann Karl Burckhardt (1773-1825) [Burckhardt 1812].

\section{REFERÊNCIAS BibLIOGRÁFICAS}

Siglas dos Arquivos das fontes primárias (manuscritos)

ANB - Arquivo Nacional do Brasil

ANTT - Arquivo nacional Torre do Tombo

AUC - Arquivo da Universidade de Coimbra

BGUC - Biblioteca Geral da Universidade de Coimbra

BNRJ - Biblioteca Nacional do Rio De Janeiro

OAUC - Observatório Astronómico da Universidade de Coimbra

\section{Fontes secundárias (bibliografia)}

ABREU, José Maria de. Legislação académica desde os Estatutos de 1772 até ao fim do anno de 1850 / colligida e coordenada por ordem do Conselheiro Reitor da Universidade de Coimbra, Coimbra: Imprensa da Universidade, 1851.

ALBUQUERQUE, António Maria Seabra de. Bibliografia da Imprensa da Universidade de Coimbra [...] de 1874 a 1875 , Coimbra, 1876

BALBI, Adrien. Essai Statistique sur le Royaume de Portugal et d'Algarve, 2 vols. Paris, 1822.

BANDEIRA, José Ramos. Universidade de Coimbra, 2 vols., Coimbra: Gráfica de Coimbra, 1943-1947.

BENNETT, Jim A.. “The English Quadrant in Europe: Instruments and the growth of consensus in practical astronomy", Journal for History of Astronomy 23 n.1 (1992), pp.1-14.

BLANKETT, John. Letters from Portugal, on the late and present state of that Kingdom/[John Blankett], London: printed for J. Almon, opposite Burlington House, in Piccadilly, [1777].

BRAGA, Teófilo. História da Universidade de Coimbra (1891-1902), 4 vols. [v.3 de 1700-1800 (1898) e v.4 de 1801 a 1872 (1902)], Lisboa, 1898-1902

BROOKS, Randall C.. "The Development of Micrometers in the Seventeenth, Eighteenth and Nineteenth centuries", Journal for the History of Astronomy 22:68 (1991), pp.127-173. CARVALHO, Rómulo de. A Astronomia em Portugal no séc. XVIII, Lisboa: Biblioteca Breve, 1985. 
CRAVEIRO, Lurdes. Manuel Alves Macomboa, arquitecto da Reforma Pombalina da Universidade de Coimbra, Instituto de História da Arte da FLUC, Série - Subsídios para a História da Arte Portuguesa, XXXI. Coimbra: Imprensa de Coimbra, 1990.

CRAVEIRO, Lurdes. "A Arquitectura da Ciência”, pp.49-101, Laboratório do Mundo. Ideias e Saberes do Século XVIII”, Catálogo de Exposição, S. Paulo, 2004.

CROARKEN, Mary. "Astronomical labourers: Maskelyne's assistants at the Royal Observatory, Greenwich, 1765-1811”, Notes Records Royal Society of London 57:3 (2003), pp.285-298.

DARQUIER de Pellepoix, Antoine. Lettres sur l'Astronomie Pratique, Paris, 1786.

DAUMAS, Maurice. Scientific Instruments of the 17th \& 18th Centuries and their Makers, Londres, 1972.

DOCUMENTOS DA REFORMA POMBALINA [DRP 1937-1979], publicados por M. Lopes d'Almeida [v.1 (1771-1782), Coimbra, 1937; v.2 (1783-1792), Coimbra, 1979], Coimbra: Universidade de Coimbra, 1937-1979.

ENCYCLOPEDIE METHODIQUE MATHEMATIQUES, par D’Alembert, Bossut, Lalande, Condorcet, et al. (3 vols.). Paris, 1784-89.

ESTATUTOS da Universidade de Coimbra compilados debaixo da immediata e suprema inspecção de El Rei D. José I pela Junta de Providencia Litteraria [...] ultimamente roborados por sua magestade na sua Lei de 28 de Agosto deste presente anno. MDCCLXXII, 3 vols., Coimbra: UC, 1972 [obra fac-similada da edição de 1772].

FIGUEIREDO, Fernando B.. José Monteiro da Rocha e a actividade científica da 'Faculdade de Mathematica' e do 'Real Observatório da Universidade de Coimbra': 1772-1820. Tese de doutoramento, Faculdade de Ciências e Tecnologia da Universidade de Coimbra, 2011.

FRANCO, Matilde Sousa. Riscos das obras da Universidade de Coimbra: o valioso álbum da Reforma Pombalina / Organizado por Matilde Pessoa de Figueiredo Sousa Franco, Coimbra: Museu Nacional de Machado de Castro, 1983.

FREIRE, Francisco de Castro. Memoria Histórica da Faculdade de Mathematica nos cem annos decoridos desde a Reforma da Universidade em 1772 até o presente, Coimbra: Imprensa da Universidade, 1872.

HUTCHINS, Roger. British University Observatories c.1820-1939: Ideals and Resources [PhD thesis, Faculty of Modern History, University of Oxford]. Oxford, 1999.

LALANDE, Jérôme. Astronomie, par M. de La Lande, 4 vols. [3 vols. em 1771 e o $4 .{ }^{\circ}$ vol. em 1781], Paris, 1771-81.

LALANDE, Jérôme. Bibliographie Astronomique, avec l'Histoire de l'Astronomie depuis 1781 jusqu'à 1802: Par Jérôme De La Lande, Paris: L'Imprimerie de la Republique, An XI [1803].

LAPLACE, Pierre Simon. Exposition du système du Monde, Paris, 1835.

LAPLACE, Pierre Simon. Mécanique Céleste, in Oeuvres complétes de Lapalace, publiées sous les auspices de L’Académie des Sciences. Paris: Gautiher-Villars, Imprimeur-libraire, 1878-1882.

LEARNER, Richard. Astronomy through the Telescope, New York: van Nostrand Reinhold Company, 1981.

LEMOS, Francisco de. Relação Geral do Estado da Universidade (1777) [edição fac-similada], Imprensa da Universidade, Coimbra, 1980.

LOBO, Rui. Os Colégios de Jesus, das Artes e de S. Jerónimo evolução e transformação no espaço urbano, DAUC, Coimbra, 1999.

MARIANO, Emília Henriques Gouveia; PINHEIRO, Manuel Augusto Moreirinhas. "O Observatório Astronómico da Universidade de Coimbra”, Universidade(s). História. Memória, Perspectivas, Actas do congresso «História da Universidade (no 7. ${ }^{\circ}$ centenário da 
sua fundação), 5 a 9 de Março de 1990, 2 vols., v.2 pp.21-53. Coimbra: Comissão organizadora do Congresso, 1991.

MARTINS, Carlos; FIGUEIREDO, Fernando B.. "O Observatório Astronómico da Universidade de Coimbra, 1772-1799”, Rua Larga 21 (2008), pp.57-61.

MARTINS, Carlos Moura. Os projectos pata o porto de São Martinho e campos de Alfeizarão, 1774-1800. As opções dos técnicos e dos políticos [Provas de Aptidão Pedagógica e Capacidade Científica, DAFCTUC]. Coimbra, 2009.

McCLELLAN, James E.. "The Academie Royale des Sciences, 1699-1793: a statistical portrait”, Isis $72: 4$ (1981), pp.541-67.

MEMÓRIAS ASTRONÓMICAS: Observatório da Marinha, 1978-1803”, Revista do Instituto Historio Geográfico Brasileiro, a. 163 n. 416 (2002), pp. 231-268.

OSÓRIO, J. Pereira. Sobre a história e desenvolvimento da Astronomia em Portugal, História e Desenvolvimento da Ciência em Portugal, publicação do $2^{\circ}$ Centenário da Academia das Ciências de Lisboa, pp.111-141, Lisboa, 1985.

PANNEKOEK, A.. A History of Astronomy, N.Y.: Dover, 1989.

PIMENTEL, António Filipe. "A cidade do Saber/Cidade do Poder. A Arquitectura da Reforma”, in [Cristina Araújo 2000, pp.265-288] [Cristina Araújo 2000] O marquês de Pombal e a universidade, Coord. Ana Cristina Araújo. Coimbra: Imprensa da Universidade, 2000.

PINTO, Rodrigo Ribeiro Sousa. "Observatório Astronómico", in Visconde de Villa-Maior, Exposição succinta da Organisação actual da Universidade de Coimbra, Coimbra, 1878.

REGULAMENTO DO REAL OBSERVATÓRIO ASTRONÓMICO DA UNIVERSIDADE DE COIMBRA. Carta Régia de 4 de Dezembro de 1799 [C.R 4-12-1799], in Ephemerides Astronómicas do Real Observatório da Universidade de Coimbra, pp.iv-xxii, Imprensa da Universidade, Coimbra 1803.

REIS, Manuel dos. "Para a história do Observatório Astronómico da Universidade de Coimbra", Revista da Faculdade de Ciências 34 (1964), pp. xxi-xxxi.

REIS, António Estácio dos. Observatório Real da Marinha (1798-1874), Lisboa: CTT Correios de Portugal, 2009.

RIBEIRO, José Silvestre. História dos estabelecimentos scientificos litterarios e artisticos de Portugal nos sucessivos reinados da monarchia, 19 vols., Lisboa: ACL, 1871-1914.

SHACKELFORD, Jole. "Tycho Brahe, Laboratory design and the aim of science. Reading plans in context", Isis 83:2 (1993), p.211-230.

TURNER, A. J.. "The observatory and the quadrant in eighteenth-century Europe", JHA, 33 part. 4 no. 113 (2002), pp. 373-385. 